\title{
Single Center Outcomes of Status Epilepticus at a Paediatric Intensive Care Unit
}

\author{
Samir Shah, Namrata Shah, Robert Johnson, Alina Nico West, Narayan Prasad
}

\begin{abstract}
Background: Status epilepticus (SE) is a frequent admission diagnosis to paediatric intensive care units (PICUs) and is associated with variable outcomes. We have audited our experience of patients presenting in SE at a Canadian PICU to determine unfavorable outcome variables. Methods: Charts of patients $<18$ years of age presenting in SE to a tertiary care PICU over a 10-year period were audited. Data were analyzed at three care-points: transport, the emergency department (ED) and the PICU. Patient outcome before PICU discharge was categorized as "favorable" for return to pre-status functioning level or "unfavorable" for new deficit/death. Student's $t$-test and $t$ he Kruskal-Wallis test were used for analysis of normal and skewed continuous variables, respectively, and either Chi-square test or Fisher's exact test for categorical variables. Results: 189 patients (54\% males) were identified with a median age of 1.9 years. Idiopathic SE had the highest incidence; infectious/vascular etiologies were associated with more unfavorable outcomes. Progression to refractory SE in the ED had a higher incidence of death $(\mathrm{p}<0.05)$. Patients with an unfavorable outcome had a higher incidence of apnea during transport $(p=0.01)$, longer hospital stays $(p<0.05)$, need for therapeutic coma $(p=0.01)$, longer duration of therapeutic coma $(p<0.05)$, need for mechanical ventilation $(\mathrm{p}<0.05)$, and recurrent or refractory seizures during inpatient stay $(\mathrm{p}<0.05)$. Multivariate analysis of unfavorable outcomes of patients in SE presenting to the PICU included renal failure, cerebral edema, apnea during transport, refractory seizures, and recurrent seizures. Conclusions: Refractory seizures in children presenting with SE are associated with worsened outcomes in the PICU.
\end{abstract}

RÉSUMÉ: Résultats cliniques chez des patients en état de mal épileptique admis dans une unité de soins intensifs pédiatriques. Contexte: L'état de mal épileptique (EME) est un diagnostic fréquent dont l'issue est variable, lors de l'hospitalisation de patients dans une unité de soins intensifs pédiatriques (USIP). Nous avons revu notre expérience chez les patients présentant un EME admis dans une USIP canadienne afin de déterminer quelles sont les variables associées à une issus défavorable. Méthode: Nous avons examiné les dossiers des patients âgés de moins de 18 ans admis en EME dans une USIP tertiaire au cours d'une période de 10 ans. Nous avons analysé les données recueillies au moment du transport, à la salle d'urgence (SU) et pendant le séjour à l'USIP. Les résultats cliniques avant le congé de l'USIP ont été classés comme étant «favorables » si le patient recouvrait son niveau de fonctionnement antérieur ou « défavorables » s'il présentait de nouveaux déficits ou s'il était décédé. Les variables continues à distribution normale ou asymétrique ont été analysées au moyen du test t de Student et du test de Kruskal-Wallis respectivement et soit du test du chi-carré ou de la méthode exacte de Ficher pour les variables qualitatives. Résultats: Nous avons identifié 189 patients, dont 54\% étaient des garçons et dont l'âge médian était de 1,9 an. L'EME idiopathique avait l'incidence la plus élevée et les étiologies infectieuses ou vasculaires étaient associées à des résultats plus défavorables. Une progression vers un EME à la SU comportait une incidence de décès plus élevée $(\mathrm{p}<0,05)$. Chez les patients chez qui le résultat clinique était défavorable nous avons observé une incidence plus élevée d'apnée pendant le transport $(\mathrm{p}=0,01)$, un séjour hospitalier plus long $(\mathrm{p}=0,05)$, la nécessité de recourir à un coma thérapeutique ( $\mathrm{p}=0,01)$, une durée plus longue du coma thérapeutique $(0,05)$, le recours à la ventilation mécanique $(\mathrm{p}=0,05)$ et des crises récidivantes ou réfractaires au traitement pendant le séjour hospitalier $(\mathrm{p}=0,05)$. L'analyse multivariée des résultats cliniques défavorables chez les patients en EME admis à l'USIP a mis en évidence les résultats défavorables suivants: l'insuffisance rénale, l'œdème cérébral, l'apnée pendant le transport, les crises réfractaires au traitement et les crises récurrentes. Conclusions: Les crises réfractaires au traitement chez les enfants admis en EME sont associées à une détérioration de l'état du patient à l'USIP.

doi:10.1017/cjn.2015.307

Can J Neurol Sci. 2016; 43: 105-112

Status epilepticus (SE) is the most common neurological emergency in childhood, with a risk of long-term neurological sequelae. ${ }^{1-3}$ Status epilepticus has been defined as a single epileptic seizure $>30$ minutes (min) in duration or two or more sequential seizures during which function is not regained. ${ }^{4}$
In clinical practice, however, shorter temporal criteria for generalized convulsive SE in adults and older children (more than five years of age) have been suggested. ${ }^{5,6}$ Currently, the most common thresholds for considering prolonged seizures as SE are 5 and 30 minutes. $^{7}$

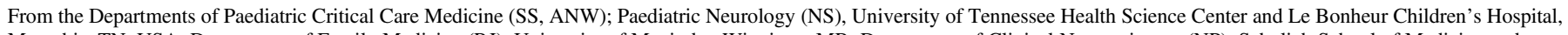
Memphis, TN, USA; Department of Family Medicine (RJ), University of Manitoba, Winnipeg, MB; Department of Clinical Neurosciences (NP), Schulich School of Medicine and

Dentistry, Children's Hospital at London Health Sciences Centre, London, ON, Canada.

Received October 23, 2015. Final Revisions Submitted July 14, 2015.

Correspondence to: Samir H Shah, Paediatric Critical Care Medicine, University of Tennessee Health Sciences Center, 50, N. Dunlap Street, \#357R, Memphis, TN, USA.

Email:sshah7@uthsc.edu. 
Epidemiological studies identify the incidence of SE to be the highest for children under the age of one year ${ }^{1,8}$ and ranging from 10-27/100,000. ${ }^{7}$ Status epilepticus etiology is poorly understood and tends to be a multifactorial condition, although the most common cause is infection. ${ }^{7}$ A population-based prospective cohort study from Finland suggests that more than one quarter of children with newly diagnosed epilepsy will experience SE, and nearly half of patients with one attack will experience a subsequent attack. The risk of SE has been deemed to be highest early in the course of paediatric epilepsy. Status epilepticus occurred prior to onset of epilepsy in over $73 \%$ of cases, and within two years of onset in $90 \%$ of cases. ${ }^{9}$ Status epilepticus associated with epilepsy is approximately $15 \%$, according to one observational study. ${ }^{10}$ A substantial proportion (16\%) of children with first ever-convulsive status epilepticus will have a recurrence within a year. Those with a previous neurological abnormality are more likely to have a recurrence. ${ }^{11}$ Risk factors that are strongly associated with SE recurrence include age at time of onset, remote symptomatic etiology, and epilepsy syndrome. ${ }^{12}$ Overall, prognosis is dependent on the underlying etiology and seizure persistence. ${ }^{13}$

Systematic studies on seizure duration in children have been few. On analysis of seizure duration in paediatric patients from ambulance and emergency room records, Shinnar, et al. found that while the mean seizure duration was approximately 12 minutes, $12 \%$ of cases presented with seizures lasting $>30$ minutes. Overall, the data suggested that if the seizure lasted for more than seven minutes there is $95 \%$ probability that it can be categorized with seizures that last for more than 30 minutes. ${ }^{14}$

Status Epilepticus outcomes from paediatric intensive care unit (PICU) accounting for variables such as transportation times, emergency department (ED) intervention, and intensive care unit (ICU) management have not yet been described. Children in SE who are admitted to the PICU are likely to represent the severe end of the spectrum of outcomes, which may reflect either the underlying cause, the treatment of SE, or both. ${ }^{15}$ While studies have described the mortality associated with SE, no studies have described the ICU-related morbidity and outcome of patients with SE. Overall mortality due to SE has declined over the past two decades because of more aggressive treatment occurring outside hospitals and stricter hospital management with clear, time-defined protocols. ${ }^{15}$ Nonetheless, prolonged SE has the potential for ICU-related morbidity, including increased duration of mechanical ventilation, hemodynamic instability, and multi-organ dysfunction. ${ }^{16}$ There are no published studies at this time evaluating SE and long-term neuropsychological outcomes.

Patient transportation and ED management can further affect SE outcomes due to temporal delays. Transport times for critically ill children in SE to tertiary care centers across Canada can be variable, with potentially longer transport times in prairie provinces. The purpose of this study was to explore the possible role of etiology of SE during the ICU course, and its effect on short-term neurological outcome of children admitted with SE to a tertiary care Canadian prairie PICU. We hypothesize that SE associated with prolonged transport times and PICU stay will lead to poor prognoses, including long-term neurological outcomes and increased morbidity. Data from PICU admissions for SE may clarify some of these issues and potentially facilitate the development of strategies to decrease the duration of SE and its complications.

\section{METHODS}

We completed a retrospective audit of all PICU admissions at the Children's Hospital of Winnipeg over a 10-year period (1994-2004). Institutional Review Board approval was obtained for the study. Patients under 18 years of age admitted to the PICU at the Children's Hospital of Winnipeg, Manitoba with prolonged ( $>30$ min) convulsive seizures were identified using a PICU-maintained database. Any patient with a diagnosis of SE that required admission to the PICU was included in the study, with the exception of those children with prolonged febrile seizures.

Demographic data, including age, weight, gender, and postal code were collected. The postal code was used to determine the location of a patient's residence (within Winnipeg or outside the city) for transport information. Patients from Winnipeg were defined as Group A and patients from outside Winnipeg were labeled as Group B. Data were collected on treatment administered prior to transport to the Children's Hospital, including treatment at home or within the community, at a nursing station, or at a community hospital. In addition, pre-PICU admission treatment details were documented, including anti-epileptic drugs (AEDs) that were administered, time of administration, and doses.

Transport data, as available, beginning from the initial site of SE management, were recorded as follows: time required for transport to Children's Hospital, and the time of administration, doses and names of the AEDs given. Apnea, failed intubations, seizure evolution to SE, and refractory SE (defined as SE that did not respond to initial treatment with a first-line AED, such as benzodiazepine, plus any additional AED) were documented during transport, in the ED, and in the PICU. Durations of PICU and hospital stay were recorded. Seizure duration was calculated from hospital records. In addition, information about recurrent seizures was noted, including number of events and response to treatment. Complications of SE assessed in the PICU included: sepsis, renal failure, hyperthermia, cardiac arrhythmias, hypotension, pulmonary edema, hypoglycemia, cerebral edema, rhabdomyolysis, hepatic failure, disseminated intravascular coagulation, apnea, anemia, syndrome of inappropriate antidiuretic hormone (SIADH), hypertension, and respiratory failure. Details of therapeutic coma in PICU were recorded, including drugs administered, duration of coma, duration of mechanical ventilation, and complications occurring secondary to mechanical ventilation. Outcome-related information recorded on patient discharge was divided into two categories based on whether the patient returned to baseline or developed new neurological deficits. New neurological deficits ranged from parental descriptions of behavioral deviations from pre-SE baseline to new abnormal neurological examination findings or new cognitive difficulties. The total number of deaths was also recorded.

Statistical analysis was performed using Student's $t$-test for normal continuous variables. Medians and interquartile ranges were reported for highly skewed variables related to duration (transport times, seizure duration, time to first AED, time in the ED, length of PICU stay, therapeutic coma duration, mechanical ventilation duration, length of hospital stay). Non-parametric analysis using the Kruskal-Wallis test was used for outcome variables and postal code variability. The Chi-square test and Fisher's exact test were used to analyze proportional variables, including transport complications, ED and PICU complications, and imaging rates for computed tomography (CT), 


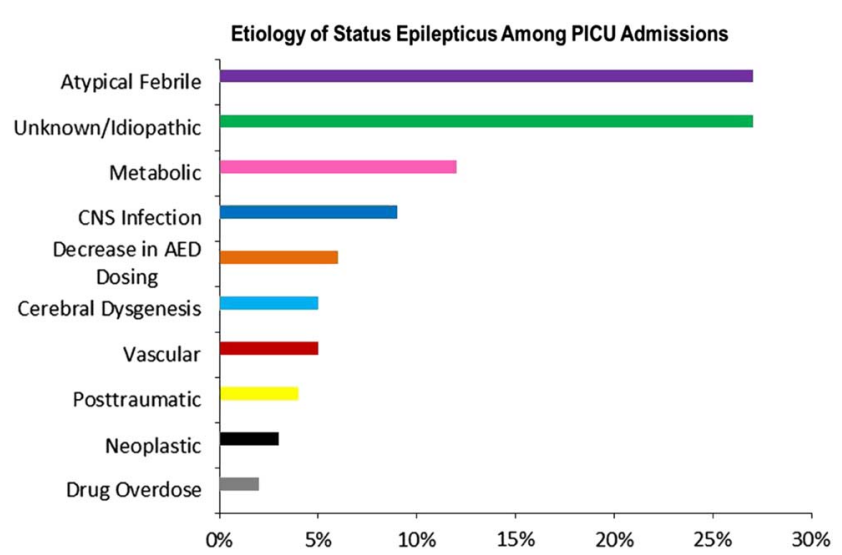

Figure 1: The etiology of paediatric status epilepticus at a single center PICU in Winnepeg, MB, Canada. Total number of patients $(n)=189$.

magnetic resonance imaging (MRI), and electroencephalography (EEG). A p-value of $<0.05$ was considered significant for all analyses.

\section{Results}

Of 230 patient charts reviewed, 189 patients met study criteria. Forty patients were excluded because of febrile seizures lasting less than 30 minutes, a seizure diagnosis was ruled out, or the chart data were incomplete. Forty patients were excluded due to febrile seizures lasting less than 30 minutes, a seizure diagnosis was ruled out, or the chart data were incomplete.

\section{Demographics}

The median age of the patients was 1.88 years (interquartile range $0.83-5.00)$. These children had a median weight of $12.00 \mathrm{~kg}$ (interquartile range 8.68-20.00). Of the 189 patients, $103(54.21 \%)$ were male, and $87(45.79 \%)$ were female.

\section{Etiology}

Status epilepticus in the ICU is heterogeneous in etiology (Figure 1). While atypical febrile seizures (febrile status epileptics) and idiopathic epilepsy were the most common presenting diagnoses, other causes included metabolic abnormalities, central nervous system infections, brain tumors, cerebral dysgenesis, AED dosing change, and drug overdose.

\section{Risk Factor-Outcome Association}

Outcome data were available on 189 patients: 132 (69.5\%) returned to neurological baseline, 46 (24.3\%) developed new neurological deficits, and $12(6.3 \%)$ died in the hospital (ED, PICU) either as a consequence of SE or ensuing complications in the PICU. Risk factors associated with unfavorable outcomes of SE patients admitted to the PICU included recurrent seizures refractory to standard management, development of systemic complications of renal failure, cerebral edema, apnea during transport, and the occurrence of recurrent breakthrough seizures requiring treatment during their hospital stay (Table 1).

\section{Transportation Times and Interventions in Relation to Outcome}

One hundred twenty five patients were from Winnipeg (Group A; 69.44\%), while 55 (30.56\%) were from outside Winnipeg (Group B). Both gender distribution and age were comparable between the two groups. The time required for transport from the location of initial management to the Children's Hospital could be determined for 121 patients (Table 2a). In addition, length of ED stay was also tabulated (Table 2a). Transportation times did not appear to influence outcome variables in the univariate analysis, despite there being a significant (expected) difference in mean transport times between patients arriving to the tertiary care center from Winnipeg versus those residents outside Winnipeg $(0.45 \mathrm{hr}$ vs. $2.05 \mathrm{hr}, \mathrm{p}<0.0001)$. Complications during transport that adversely affected the outcome included the occurrence of apnea (Table 2b), septic shock, and dysrhythmias. Most patients who developed new deficits experienced apnea during transport (34\%). During transport, the initial AED dose was inadequate in 34 patients (Table 2b; $15.38 \%$ in Group A, $13.64 \%$ in Group B). However, most of these patients returned to baseline and did not have a significant effect on outcome. Overall, SE mortality in transport was due to respiratory distress during apneic episodes in transport or in the ED or complications from refractory SE, yet this data was not statistically significant (Table $2 b$ ).

\section{Emergency Department Interventions}

Patients transported from the city presented in sustained SE to the ED at a higher percentage than those transported from outside (40.91\% of Group A patients vs. 9.38\% Group B patients; $\mathrm{p}=0.0008$ ). Emergency department complications are shown in Table 2b. Approximately $61 \%$ of patients experienced apnea,

Table 1: Variables adversely impacting outcome in children presenting to a PICU

\begin{tabular}{|c|c|c|}
\hline Predictor Variable & Adjusted OR & $95 \% \mathrm{CI}$ \\
\hline Recurrent Seizures during ICU Treatment & 2.461 & $1.099-5.512$ \\
\hline Refractory Status Epilepticus & 3.858 & $1.062-14.022$ \\
\hline Transport Apnea & 4.546 & $1.859-11.118$ \\
\hline Recurrent seizures in Clinical Teaching Units & 5.003 & $1.800-13.910$ \\
\hline Renal Failure in PICU & 8.087 & $1.343-48.693$ \\
\hline Cerebral Edema & 12.438 & $3.418-45.265$ \\
\hline
\end{tabular}

$\mathrm{ICU}=$ intensive care unit; $\mathrm{PICU}=$ pediatric intensive care unit 
Table 2a: Transport and ED Management Duration of Patients with Status Epilepticus

\begin{tabular}{l|l|c|c|c|c|c}
\hline Length of Time in hours & & Total Number of Patients & $\begin{array}{c}\text { Patients who returned } \\
\text { to baseline }\end{array}$ & Patients with New Deficits & Patients who died & p-value \\
\hline (Interquartile Range) & Transport to ED & $0.65(0.37-1.73)$ & $0.58(0.36-1.37)$ & $1.30(0.47-2.53)$ & $0.42(0.31-2.29)$ & NS \\
\hline & ED Stay & $2.67(2.00-3.58)$ & $2.48(1.88-3.53)$ & $3.31(2.58-4.25)$ & $2.31(1.75-3.00)$ & NS \\
\hline
\end{tabular}

Table 2b: Transport and ED Complications of Patients with Seizures

\begin{tabular}{|c|c|c|c|c|c|c|}
\hline Location of Management & Complication & Total Patients & Returned to Baseline & New Deficits & Death & p-value \\
\hline \multirow[t]{4}{*}{ Transport Management $(n=121)$} & Apnea & 47 & 27 & 16 & 4 & ${ }^{*} \mathrm{p}=0.0054$ \\
\hline & Developed SE & 26 & 20 & 6 & 0 & NS \\
\hline & Refractory SE & 10 & 7 & 2 & 1 & NS \\
\hline & Failed $1^{\text {st }}$ AED dose $(\mathbf{n}=\mathbf{3 4})$ & 7 & 5 & 2 & 0 & NS \\
\hline \multirow[t]{5}{*}{ ED Management $(n=128)$} & Apnea & 78 & 60 & 14 & 4 & NS \\
\hline & Failed Intubation & 1 & 1 & 0 & 0 & NS \\
\hline & Developed SE & 40 & 32 & 8 & 0 & NS \\
\hline & Refractory SE & 21 & 13 & 3 & 5 & $* \mathrm{p}<0.0001$ \\
\hline & Failed $1^{\text {st }}$ AED dose $(\mathbf{n}=\mathbf{1 0 5})$ & 15 & 12 & 3 & 0 & NS \\
\hline
\end{tabular}

*Significant $\mathrm{p}$ values. NS = not significant; $\mathrm{ED}=$ emergency department; $\mathrm{SE}=$ status epilepticus; $\mathrm{AED}=$ anti-epileptic drugs.

Table 3a: Duration of PICU SE Management and Relationship to Deficit Development and Mortality

\begin{tabular}{|c|c|c|c|c|}
\hline Time (hours) & Returned to Baseline & Patients with New Deficits & Patients who Died & p-value \\
\hline Seizure Duration $(\mathbf{n}=\mathbf{1 7 6})$ & $0.70(0.42-1.13)$ & $0.66(0.12-1.38)$ & $1.30(0.42-2.50)$ & NS \\
\hline Time to $1^{\text {st }}$ AED $(\mathbf{n}=\mathbf{1 8 1})$ & $0.47(0.25-1.37)$ & $0.42(0.17-0.88)$ & $0.28(0.10-0.75)$ & NS \\
\hline Duration of Mechanical Ventilation $(\mathbf{n}=\mathbf{1 2 5})$ & $8.75(3.95-21.62)$ & $24.50(12.12-102.70)$ & $74.25(27.58-150.10)$ & $* \mathrm{p}<0.0001$ \\
\hline Duration of Therapeutic Coma $(\mathbf{n}=\mathbf{8})$ & $5.73(4.22-7.25)$ & $30.29(17.5-43.79)$ & $77.38(75.50-79.25)$ & $* \mathrm{p}=0.0498$ \\
\hline Length of Hospital Stay $(\mathbf{n}=\mathbf{1 8 8})$ & $97.08(63.25-172.30)$ & $253.33(82.52-607.20)$ & $564.38(170.13-1769.72)$ & $* \mathrm{p}<0.0001$ \\
\hline
\end{tabular}

Table 3b: SE Management and Complication Development in Relationship to SE Outcomes

\begin{tabular}{|c|c|c|c|c|c|}
\hline & & Returned to Baseline & $\begin{array}{l}\text { Patients with } \\
\text { New Deficits }\end{array}$ & $\begin{array}{l}\text { Patients who } \\
\text { Died }\end{array}$ & p-value \\
\hline \multirow[t]{2}{*}{ Type of Management } & Central Venous Access $(\mathbf{n}=\mathbf{2 5 / 1 8 9})$ & 9 & 9 & 7 & $* \mathrm{p}<0.0001$ \\
\hline & Arterial Line $(\mathbf{n}=\mathbf{2 5 / 1 8 9})$ & 5 & 13 & 7 & $* \mathrm{p}<0.0001$ \\
\hline \multirow[t]{9}{*}{ Complication During Length of Stay } & Seizures on Arrival $(\mathbf{n}=\mathbf{5 8 / 1 8 6})$ & 40 & 13 & 5 & NS \\
\hline & Recurrent Seizures $(\mathbf{n}=\mathbf{9 8 / 1 8 9})$ & 57 & 32 & 9 & $* \mathrm{p}=0.0021$ \\
\hline & Refractory Seizures $(n=\mathbf{1 7 / 1 8 9})$ & 6 & 9 & 2 & $* \mathrm{p}=0.0056$ \\
\hline & Therapeutic Coma $(\mathbf{n}=\mathbf{8 / 1 8 9})$ & 2 & 4 & 2 & $* \mathrm{p}=0.0096$ \\
\hline & Ventilator-Induced Pneumonia $(\mathbf{n}=\mathbf{1 8} / \mathbf{1 2 5})$ & 15 & 3 & 0 & NS \\
\hline & Extubation Failure $(\mathbf{n}=\mathbf{1 / 1 2 5})$ & 1 & 0 & 0 & NS \\
\hline & Post-Extubation Stridor $(n=\mathbf{2 6 / 1 2 5})$ & 16 & 6 & 4 & NS \\
\hline & Other Ventilator Complications $(\mathbf{n}=\mathbf{3 4 / 1 2 5})$ & 21 & 11 & 2 & NS \\
\hline & AED-induced Respiratory Depression $(\mathbf{n}=\mathbf{5 5} / \mathbf{1 8 9})$ & 44 & 8 & 3 & NS \\
\hline
\end{tabular}

*Significant value; $\mathrm{NS}=$ not significant; $\mathrm{SE}=$ status epilepticus; $\mathrm{AED}=$ anti-epileptic drugs. 
Table 4: Impact of PICU Complications on SE Outcomes

\begin{tabular}{|c|c|c|c|c|c|}
\hline Complication & $\mathbf{n}^{\dagger}$ & Returned to Baseline & Patients With New Deficits & Patients Who Died & p value \\
\hline Infection & 87 & 56 & 24 & 7 & NS \\
\hline Renal Failure & 11 & 2 & 4 & 5 & $* \mathrm{p}<0.0001$ \\
\hline Hyperthermia & 49 & 28 & 17 & 4 & NS \\
\hline Acidosis & 21 & 12 & 4 & 5 & $* \mathrm{p}=0.0022$ \\
\hline Cardiac Arrhythmias & 7 & 2 & 2 & 3 & $* \mathrm{p}=0.0002$ \\
\hline Hypotension & 8 & 2 & 3 & 3 & $* p=0.0004$ \\
\hline Pulmonary Edema & 2 & 0 & 0 & 2 & $* \mathrm{p}<0.0001$ \\
\hline Hypoglycemia & 6 & 1 & 3 & 2 & $* p=0.0034$ \\
\hline Cerebral Edema & 22 & 4 & 14 & 4 & $* \mathrm{p}<0.0001$ \\
\hline Hepatic Failure & 5 & 0 & 2 & 3 & $* \mathrm{p}<0.0001$ \\
\hline DIC & 2 & 0 & 1 & 1 & $* \mathrm{p}=0.0177$ \\
\hline Increased ICP & 11 & 3 & 3 & 5 & $* \mathrm{p}<0.0001$ \\
\hline Apnea & 10 & 6 & 2 & 2 & NS \\
\hline Anemia & 19 & 8 & 7 & 4 & $* p=0.0042$ \\
\hline SIADH & 11 & 3 & 7 & 1 & $* p=0.0049$ \\
\hline Hypertension & 5 & 1 & 3 & 1 & $* \mathrm{p}=0.0486$ \\
\hline Respiratory Failure & 4 & 1 & 0 & 3 & $* \mathrm{p}<0.0001$ \\
\hline Other Complications & 67 & 33 & 23 & 11 & $* \mathrm{p}<0.0001$ \\
\hline Inadequate $1^{\text {st }} \mathrm{AED}$ Dose $\mathrm{F}^{\ddagger}$ & 68 & 50 & 14 & 4 & NS \\
\hline Median PICU LOS ${ }^{\bullet}$ & 189 & $24.43(14.77-42.50)$ & $50.42(23.17-116.38)$ & $58.98(37.00-182.74)$ & $\mathrm{p}<0.0001$ \\
\hline
\end{tabular}

NS = not significant; PICU = pediatric intensive care unit; SE = status epilepticus; DIC = Disseminated Intravascular Coagulation; $\mathrm{ICP}=$ intracranial pressure; $\mathrm{AED}=$ anti-epileptic drugs; $\mathrm{SIADH}=$ syndrome of inappropriate anti-diuretic hormone $; \mathrm{LOS}=$ length of stay.

* Significant $\mathrm{p}$ values.

${ }^{\dagger} \mathrm{n}$ represents number of patients with specified complication out of total $n=189$.

${ }^{\ddagger}$ Total $n=136$. For all other complications, total $n=189$.

'Median PICU Length of Stay (LOS) in hours with Interquartile Ranges in parentheses.

followed by $31 \%$ that developed SE in the ED, although they did not lead to significant outcomes. Sixteen percent of patients developed refractory $\mathrm{SE}$ in the $\mathrm{ED}$, however, $62 \%$ returned to baseline (Table 2b). Eighteen percent of patients who developed new deficits experienced apnea in the ED, almost half the number of patients that experienced apnea during transport. Mortality of SE patients in the ED was significantly attributable to refractory SE (55\%).

\section{PICU Stay and Complications}

The median duration of PICU stay was 34.38 hours (interquartile range, 16.25-59.17). The duration of transport (related to geographical distribution) did not adversely influence outcome variables. A similar proportion of patients from Winnipeg and outside of Winnipeg were admitted to the PICU on each of the three shifts (7 a.m. to 3 p.m., 3 p.m. to 11 p.m., and 11 p.m. to 7 a.m.). The time of day at which the patients were admitted was not significantly correlated with outcome. The most common indication for PICU admission was the need for mechanical ventilator support. Patient mortality, followed by new deficit development, was significantly correlated to longer duration of mechanical ventilation and therapeutic coma and increased length of hospital stay (Table 3a). Group B patients had significantly longer hospital stays $(p=0.0396)$ and were mechanically ventilated longer $(\mathrm{p}=0.0037)$ than Group A counterparts residing within the city of
Winnipeg (data not shown). Yet, the need for central venous access or continuous arterial pressure monitoring also correlated with poor outcomes (Table 3b). Patients with recurrent breakthrough seizures after hospitalization and those with refractory recurrent breakthrough seizures had poorer outcomes than those without recurrent seizures (Table $3 b$ ).

Many of the complications in the PICU had significant effects on outcome, including renal failure, acidosis, cardiac arrhythmias, hypotension, pulmonary edema, hypoglycemia, cerebral edema, hepatic failure, disseminated intravascular coagulation, anemia, SIADH, hypertension, respiratory failure, and other complications (Table 4). The occurrence of cerebral edema and the presence of anemia were significantly associated with a poor outcome in Group B patients $(\mathrm{p}=0.0104$ and $\mathrm{p}=0.0381$, respectively).

\section{DisCUSSION}

To our knowledge, this is the first study to review outcome variables of children presenting in SE at a single-center PICU while determining its risk factors, management and overall outcome. Based on the information analyzed in the small number of patients in this cohort, we were unable to correlate etiology to PICU outcomes. Although SE has a heterogeneous etiology, children with atypical febrile seizures constitute a significantly 
large proportion of patients requiring intensive care. In fact, idiopathic epilepsy and febrile status epilepticus combined accounted for $50 \%$ of the patients admitted to the PICU. The incidence of SE decreases by $25-40 \%$ based on exclusion of febrile SE, indicative of its common etiology. ${ }^{17}$ In our study, etiologies could be surmised from the evolution of illness in our PICU patients. Infection was a major complication for 87 of 189 patients (Table 3). Although there was no significant effect on outcome and most patients returned to baseline, this data does offer insight into common etiologies of SE. In a prospective cohort of patients with febrile SE reported by Shinnar et al., ${ }^{18}$ the short-term outcome was considered good because the morbidity and mortality were low. It is known that viral triggers are associated with febrile SE, however, recent reports link infection with afebrile SE. ${ }^{19}$ In our cohort of patients admitted to the PICU, 9\% were identified as having a primary central nervous system infection (Figure 1). Although infectious agents were not identified, our data is consistent with studies demonstrating that several viruses, including human herpes virus-6, human herpes virus- 7 and others, are causes of febrile SE. ${ }^{19}$ While the immediate outcomes of SE following such primary infections appear to be good, the long-term outcomes with regard to behavior, cognitive function, and the delayed development of epilepsy remain unclear. Paediatric post-traumatic brain injury patients are at increased risk of subclinical and clinical SE detected via continuous EEG monitoring. ${ }^{20}$ Brain injury sequelae include PICU complications seen in this study - seizures evolving to SE, increased inracranial pressure, hyperthermia, cerebral edema, and SIADH, ${ }^{21-23}$ which significantly attributed to SE outcomes. It is unknown at this time if patients in our study manifested these complications based upon an established diagnosis of traumatic or anoxic brain injury, although $4 \%$ of our cases occurred after trauma (Figure 1). However, in retrospect, it is suspected that they developed aforementioned sequelae, including SE, due to brain injury.

Aggressive first-line treatment to stabilize patients in SE has improved yet still remains challenging, given multiple etiologies, e.g. $27 \%$ of our patients presented in febrile SE (Figure 1), possibly related to prolonged time in transport or lack of immediate administration of AED. The addition of extraneous variables, including prolonged transport times and failure of AED administration tend to complicate treatment in the ED and can lead to subsequent PICU admission. Transport times, in our study, was not significant in determining outcomes, likely due to the number of patient records reviewed. Despite the p-values, it is yet noteworthy to mention that longer transport times may still lead to development of new deficits in patients. Additionally, transport apnea was a significant complication (Table 1). Apnea is a known complication of emergency transport and can lead to increased mortality. ${ }^{24}$ Future retrospective studies with a larger cohort might yield more insight into the etiology, as well as transport times and time to first AED administration as possible risk factors for SE onset and development of SE and complications.

During ED and PICU management of SE, refractory and recurrent SE were significant complications throughout the hospital course that adversely affect outcomes (Tables $1 \mathrm{~b}$ and $2 \mathrm{~b}$ ). The mortality rate of patients who develop in-hospital SE vary from $32 \%-60 \%$, however, there are no studies comparing this to mortality rates of those who develop out-of-hospital SE. ${ }^{25}$ There is virtually no data supporting that the incidence of prolonged and refractory SE may be influenced by geographic location (countryor region-specific data) and that the cause of SE cannot be ascertained based on increased transport times to a medical facility from a rural area.

Despite differences in initial treatments provided at the patient's geographic location, rates of admission to the PICU did not differ. Roughly $15 \%$ of all patients received inadequate dosages of their AED medications, at the site of initial treatment as well as in the ED. In addition to inadequate dosing, a significant proportion of children admitted to the PICU received not only inadequate doses of the rescue medication (benzodiazepine) but subsequent doses of first and second line AEDs administered during transport and in the ED. The reasons for this remain unclear, but could be related to caution regarding the problem of respiratory depression secondary to the use of combinations of benzodiazepines and phenobarbital. As this phenomenon was not consistently observed, variables such as individual physician preferences, calculations, and weight errors may exist in treatment administration. All treatment protocols issued to parents and used by the prescribing practice, by transport teams, in the ED, and the PICU should emphasize the importance of ascertaining patient weight accurately in order to reduce the chances of inadequate treatment. Inadequate dosing may have been an unrecognized variable that influenced the occurrence of self-sustained SE. This observation has been made in other studies. ${ }^{11}$

The development of refractoriness to AED therapy remains one of the enduring challenges in the management of SE, especially in the ICU setting. ${ }^{26,27}$ In our patient cohort, we identified 17 (9\%) patients admitted to the PICU who evolved to a state of treatmentrefractory status epilepticus. Of these, eight $(\sim 50 \%)$ required the induction of therapeutic coma using pentobarbital. Four patients were left with fresh neurological deficits, and two patients died. We used high-dose suppression therapy such as pentobarbital and midazolam with EEG monitoring for management of refractory SE as suggested for treatment refractoriness to conventional measures. ${ }^{15,28}$ The role of newer therapeutic alternatives for the management of status epilepticus has been described. ${ }^{15,29}$ Several case series and open label trials have reported success with use of AEDs including intravenous valproic acid, ${ }^{30-32}$ topiramate $^{33-35}$ and levetiracetam..$^{30,36,37}$ Increasing experience with these may provide additional options, prior to the consideration of high-dose suppression therapy in the ICU. Other paediatric SE studies suggest that the outcome of patients treated with high-dose suppression therapy is independent of the specific coma-inducing agents or the extent of EEG burst suppression, suggesting that the primary etiology may be a key determinant of outcome. ${ }^{38}$ Additionally, it is known that pentobarbital causes hypotension and is associated with nosocomial infections due to white blood cell dysfunction. ${ }^{39}$

Paediatric ICU complications associated with adverse outcomes include infection, cerebral edema, increased ICP, and renal failure. Infection has already been discussed as a complication of the etiology of the seizure. Increased ICP, SIADH, and cerebral edema are all related to SE etiology, specifically brain injury. Renal failure is a less specific seizure complication, but significant nevertheless to SE outcomes in this study. Acute renal failure is a commonly associated complication of seizures and SE, likely due to rhabdomyolysis from increased muscular activity during seizure. Moreover, infection increases susceptibility to acute renal failure. ${ }^{40}$ Creatine kinase levels were not measured in any of the patients in our study, especially with either increased refractory or recurrent seizures, however, it is likely that these patients developed renal failure. The cause of renal failure in our patients is 
unknown but likely secondary to the seizure and musculoskeletal overactivity. With increased confidence intervals for renal failure and cerebral edema odds ratios, more data would need to be collected in order to determine if renal failure and cerebral edema are variables truly indicative of worsening outcomes.

There are few studies of long-term outcomes among children who experienced SE requiring PICU admission, although it has been reported that children with EEG-monitored status epilepticus have worsened outcomes. ${ }^{41}$ In general, our retrospective data point to a favorable outcome for the majority $(\sim 70 \%)$, and considerable morbidity in the form of added neurological deficits (24\%), with mortality rates that are very similar to other reported studies. ${ }^{11}$ The risk of subsequent epilepsy (13-74\%), and of recurrent SE (3-56\%) varies across published studies and meta-analyses. ${ }^{42}$

There are several limitations to this study: inclusion of a small number of subjects, limiting the statistical analysis; incomplete or missing datasets; a selection bias towards the sickest patients in SE; seizure types that could not be classified accurately from the abstracted data; unclassified types of SE; outcomes that were chosen upon discharge leading to deficits that may not have been recorded; failure to correlate longer transport times and PICU stay with new deficits acquired during transport; and, finally, long-term follow-up outcomes with deficit specification remain unreported. Additionally, in Table 2a, new deficits acquired during transport did not correlate with longer transport times and PICU stays. However, this would be better addressed with a prospective analysis.

\section{CONCLUSIONS}

Our clinical findings impart a sense of urgent need to establish risk factors of paediatric SE and its complications during the hospital course, recognize the challenges in the management of paediatric status epilepticus to prevent the significant morbidity associated with epilepsy, as well as the long-term comorbidities in the form of behavioral and neurocognitive impairments.

\section{ACKNOWLEDGMENTS}

The authors thank the B. Sc. Medicine program at the University of Manitoba for the stipendiary support for Dr. R. Johnson; the Manitoba Institute of Child Health (Monagle, \#33) and the Children's Hospital Foundation of Manitoba for a their support and Ms. Pamela Cate and Mrs. Andrea Patters for their editorial assistance.

\section{Disclosures}

Samir Shah, Namrata Shah, Robert Johnson, Alina Nico West, and Narayan Prasad do not have anything to disclose.

No financial support was received for this study.

\section{REFERENCES}

1. DeLorenzo RJ, Hauser WA, Towne AR, et al. A prospective, population-based epidemiologic study of status epilepticus in Richmond, Virginia. Neurology. 1996;46:1029-35.

2. Scott RC, Surtees RA, Neville BG. Status epilepticus: pathophysiology, epidemiology, and outcomes. Arch Dis Child. 1998;79:73-7.

3. Hussain N, Appleton R, Thorburn K. Aetiology, course and outcome of children admitted to paediatric intensive care with convulsive status epilepticus: a retrospective 5-year review. Seizure. 2007; 16:305-12.

4. Treatment of convulsive status epilepticus. Recommendations of the Epilepsy Foundation of America's Working Group on Status Epilepticus. JAMA. 1993;270:854-9.
5. Lowenstein DH, Bleck T, Macdonald RL. It's time to revise the definition of status epilepticus. Epilepsia. 1999;40:120-2.

6. Meldrum BS. The revised operational definition of generalised tonicclonic (TC) status epilepticus in adults. Epilepsia. 1999;40:123-4.

7. Sánchez Fernández I, Abend NS, Agadi S, et al. Gaps and opportunities in refractory status epilepticus research in children: a multi-center approach by the Pediatric Status Epilepticus Research Group (pSERG). Seizure. 2014;23:87-97.

8. Hesdorffer DC, Logroscino G, Cascino G, et al. Incidence of status epilepticus in Rochester, Minnesota, 1965-1984. Neurology. 1998;50:735-41.

9. Sillanpaa M, Shinnar S. Status epilepticus in a population-based cohort with childhood-onset epilepsy in Finland. Ann Neurol. 2002;52:303-10.

10. Sutter R, Marsch S, Fuhr P, et al. Mortality and recovery from refractory status epilepticus in the intensive care unit: a 7-year observational study. Epilepsia. 2013;54:502-11.

11. Chin RF, Neville BG, Peckham C, et al. Incidence, cause, and short-term outcome of convulsive status epilepticus in childhood: prospective population-based study. Lancet. 2006;368:222-9.

12. Shinnar S, Pellock JM, Moshé SL, et al. In whom does status epilepticus occur: age-related differences in children. Epilepsia. 1997;38:907-14.

13. Abend NS, Loddenkemper T. Management of pediatric status epilepticus. Curr Treat Options Neurol. 2014;16:301.

14. Shinnar S, Berg AT, Moshe SL, et al. How long do new-onset seizures in children last? Ann Neurol. 2001;49:659-64.

15. Wilkes R, Tasker RC. Pediatric intensive care treatment of uncontrolled status epilepticus. Crit Care Clin. 2013;29:239-57.

16. Abend NS, Gutierrez-Colina AM, Dlugos DJ. Medical treatment of pediatric status epilepticus. Semin Pediatr Neurol. 2010;17:169-75.

17. Singh RK, Gaillard WD. Status epilepticus in children. Curr Neurol Neurosci Rep. 2009;9:137-44.

18. Shinnar S, Pellock JM, Berg AT, et al. Short-term outcomes of children with febrile status epilepticus. Epilepsia. 2001;42:47-53.

19. Juntunen A, Herrgård E, Mannonen L, et al. A major role of viruses in convulsive status epilepticus in children: a prospective study of 22 children. Eur J Pediatr. 2001;160:37-42.

20. Arndt DH, Lerner JT, Matsumoto JH, et al. Subclinical early posttraumatic seizures detected by continuous EEG monitoring in a consecutive pediatric cohort. Epilepsia. 2013;54:1780-8.

21. Agha A, Phillips J, O'Kelly P, et al. The natural history of post-traumatic hypopituitarism: implications for assessment and treatment. Am J Med. 2005;118:1416.

22. Moppett IK. Traumatic brain injury: assessment, resuscitation and early management. Br J Anaesth. 2007;99:18-31.

23. Walker PA, Harting MT, Baumgartner JE, et al. Modern approaches to pediatric brain injury therapy. J Trauma. 2009;67:S120-7.

24. Nakayama DK, Gardner MJ, Rowe MI. Emergency endotracheal intubation in pediatric trauma. Ann Surg. 1990;211:218-23.

25. Sutter R, Kaplan PW, Ruegg S. Outcome predictors for status epilepticus-what really counts. Nat Rev Neurol. 2013;9:525-34.

26. Holtkamp M, Othman J, Buchheim K, et al. Predictors and prognosis of refractory status epilepticus treated in a neurological intensive care unit. J Neurol Neurosurg Psychiatry. 2005;76:534-9.

27. Drislane FW, Lopez MR, Blum AS, et al. Detection and treatment of refractory status epilepticus in the intensive care unit. J Clin Neurophysiol. 2008;25:181-6.

28. Wilkes R, Tasker RC. Intensive care treatment of uncontrolled status epilepticus in children: systematic literature search of midazolam and anesthetic therapies. Pediatr Crit Care Med. 2014;15:632-9.

29. Wheless JW. Treatment of refractory convulsive status epilepticus in children: other therapies. Semin Pediatr Neurol. 2010;17:190-194.

30. Wheless JW, Treiman DM. The role of the newer antiepileptic drugs in the treatment of generalized convulsive status epilepticus. Epilepsia. 2008;49:74-8.

31. Mehta V, Singhi P, Singhi S. Intravenous sodium valproate versus diazepam infusion for the control of refractory status epilepticus in children: a randomized controlled trial. J Child Neurol. 2007;22:1191-7.

32. Yu KT, Mills S, Thompson N, et al. Safety and efficacy of intravenous valproate in pediatric status epilepticus and acute repetitive seizures. Epilepsia. 2003;44:724-6. 
33. Perry MS, Holt PJ, Sladky JT. Topiramate loading for refractory status epilepticus in children. Epilepsia. 2006;47:1070-1.

34. Blumkin L, Lerman-Sagie T, Houri T, et al. Pediatric refractory partial status epilepticus responsive to topiramate. J Child Neurol. 2005;20:239-41.

35. Kahriman M, Minecan D, Kutluay E, et al. Efficacy of topiramate in children with refractory status epilepticus. Epilepsia. 2003;44:1353-6.

36. Wheless JW, Clarke DF, Carpenter D. Treatment of pediatric epilepsy: expert opinion, 2005. J Child Neurol. 2005;20(Suppl 1):S1-56; quiz S59-60.

37. Patel NC, Landan IR, Levin J, et al. The use of levetiracetam in refractory status epilepticus. Seizure. 2006;15:137-41.
38. Rossetti AO, Logroscino G, Bromfield EB. Refractory status epilepticus: effect of treatment aggressiveness on prognosis. Arch Neurol. 2005;62:1698-702.

39. Pugin D, Foreman B, De Marchis GM, et al. Is pentobarbital safe and efficacious in the treatment of super-refractory status epilepticus: a cohort study. Crit Care. 2014;18:R103.

40. Huerta-Alardin AL, Varon J, Marik PE. Bench-to-bedside review: Rhabdomyolysis - an overview for clinicians. Crit Care. 2005; 9:158-69.

41. Tasker RC. Status epilepticus in children. Curr Opin Pediatr. 2014.

42. Chin RF, Neville BG, Scott RC. A systematic review of the epidemiology of status epilepticus. Eur J Neurol. 2004;11:800-10. 